\title{
Different Selection Principles of Freestanding and Bound Morphemes in Language Production
}

\author{
Niels O. Schiller \\ Maastricht University, Max Planck Institute for \\ Psycholinguistics, and Leiden Institute for Brain and Cognition
}

\author{
Albert Costa \\ Universitat de Barcelona
}

\begin{abstract}
Freestanding and bound morphemes differ in many (psycho)linguistic aspects. Some theorists have claimed that the representation and retrieval of freestanding and bound morphemes in the course of language production are governed by similar processing mechanisms. Alternatively, it has been proposed that both types of morphemes may be selected for production in different ways. In this article, the authors first review the available experimental evidence related to this topic and then present new experimental data pointing to the notion that freestanding and bound morphemes are retrieved following distinct processing principles: freestanding morphemes are subject to competition, bound morphemes not.
\end{abstract}

Keywords: psycholinguistics, language production, gender congruency, freestanding and bound morphemes, open and closed class words

Two types of word classes can be distinguished in language processing, that is, open class and closed class words. Although diachronically, for instance, morphemes from the open class can become members of the closed class, synchronically the set of closed class morphemes is stable, whereas the set of open class morphemes can be rather variable, for example, because of new words intruding into the language. Open class morphemes include nouns, verbs, adjectives, and adverbs. Closed class morphemes, in contrast, include so-called function words such as determiners, prepositions, pronouns, auxiliaries, and conjunctions, as well as inflectional and derivational affixes (Bock \& Levelt, 1994). Open and closed class morphemes differ in many aspects, for instance, their frequency of occurrence, their age of acquisition, and their predisposition to be involved in speech errors (but see Dell, 1990). Garrett (1982) argued that closed class morphemes are a special set

Niels O. Schiller, Department of Cognitive Neuroscience, Faculty of Psychology, Maastricht University, Maastricht, the Netherlands; Max Planck Institute for Psycholinguistics, Nijmegen, the Netherlands; and Leiden Institute for Brain and Cognition, Leiden, the Netherlands. Albert Costa, Faculty of Psychology, Universitat de Barcelona, Barcelona, Spain.

Niels O. Schiller was supported by Grant 453-02-006 from the Netherlands Organisation for Scientific Research (NWO) and by Macquarie University Research Development Grant 04/1850-03. Albert Costa was supported by Grant SEJ2005-00409 from the Spanish government and by Grant "Bridging Mind, Brain, and Behavior" from the McDonnell Foundation.

The experiments reported in this study were carried out at the Max Planck Institute for Psycholinguistics in Nijmegen, the Netherlands. The article was partly written while Niels O. Schiller was a visitor at the Macquarie Centre for Cognitive Science, Macquarie University, Sydney, New South Wales, Australia. We thank Franziska Schwarz and Constance Hendrickx for their help with carrying out the experiment.

Correspondence concerning this article should be addressed to Niels O. Schiller, Department of Cognitive Neuroscience, Faculty of Psychology, Maastricht University, P.O. Box 616, 6200 MD Maastricht, the Netherlands. E-mail: n.schiller@psychology.unimaas.nl of morphemes in the vocabulary because they are often absent in the speech of agrammatic aphasic speakers and less likely to occur in speech errors than open class morphemes. Garrett (1982) suggested that closed class morphemes form intrinsic parts of the grammatical frame that speakers generate when they produce utterances. This hypothesis can account for morphological stranding errors like you ordered up ending some fish dish (from Garrett, 1993) by assuming that the inflectional affixes for the past tense $(-e d)$ and the progressive tense (-ing) are part of the frame itself, whereas the verbs (i.e., order and end) have to be inserted. Therefore, they can be erroneously exchanged although the affixes stay in their place.

This idea was further developed by Lapointe (1985), who investigated the speech of English and Italian agrammatic patients and found that freestanding and bound closed class morphemes behaved differently in the simplifications of speech made by these aphasics. More precisely, inflectional affixes were mostly substituted, whereas function words were generally omitted, suggesting that it may be necessary to treat these two types of closed class morphemes differently in a processing model. Therefore, Lapointe and Dell (1989) proposed a modified account of Garrett's (1982) view of how closed class morphemes are produced. They distinguished between freestanding closed class morphemes, such as determiners, and bound closed class morphemes, such as inflectional affixes. In their account, there are two types of positional frames, namely phrase fragments and function word fragments. Affixes form directly part of phrase fragments, whereas freestanding function words are represented in function word fragments. That is, function words fall in between regular lexical items and inflectional affixes in terms of their properties. The important claim Lapointe and Dell (1989) made is that during lexical retrieval, the production system is not concerned with accessing function words because they are already stored in syntactic fragments and accessed separately. Instead, the system can concentrate on retrieving lexical items for each phrase fragment to be filled in. Thus, in contrast to Garrett (1982), who assumed that freestanding 
function words and bound morphemes are processed in a uniform way in language production, Lapointe and Dell (1989) argued that freestanding closed class morphemes, such as determiners, need to be treated distinctly from bound closed class morphemes, such as inflectional affixes.

The information needed to retrieve freestanding and bound morphemes, which are eventually combined to produce meaningful grammatical utterances, varies across languages. For example, in languages like Dutch or Spanish, the selection of a determiner form that accompanies a noun in noun phrases (NPs) is partially driven by a property of the head noun called grammatical gender (e.g., Dutch nouns with common gender take the definite determiner $d e$ and nouns with neuter gender take the definite determiner het). Along the same lines, some adjectives carry an inflected morpheme that agrees with the noun's grammatical gender; in Dutch, adjectives that modify nouns with common gender add a schwa [i.e. $/ \partial /$ ] to the stem in adjective NPs, for example, groene $_{\text {com }}$ vaas $_{\text {com }}$ [green vase] versus groen $_{\text {neu }}$ boek $_{\text {neu }}$ [green book] $(\mathrm{com}=$ common gender; neu $=$ neuter gender; differences are highlighted in bold). Thus, a noun's grammatical gender is a crucial piece of information necessary to retrieve freestanding morphemes (such as the gender-marked determiners het or de) as well as bound morphemes (such as the gender-marked adjective inflection $-e$ ). The theoretical question that models of speech production need to address is whether these morphemes-given their different morphological and syntactic status-are retrieved following the same processing principles (see e.g., Garrett, 1982, vs. Lapointe \& Dell, 1989).

Supporting Garrett's (1982) view, Schriefers, Jescheniak, and Hantsch (2005) recently argued that freestanding and bound morphemes are processed in similar ways. They provided a series of experiments in which native German participants named pictures either in the singular or in the plural by using different utterance formats (i.e., bare noun, determiner + adjective + noun, and adjective + noun). Their main finding was an interaction between number and gender when participants produced determiner + adjective NPs (e.g., das neu große $_{\text {neu }}$ Haus $_{\text {neu }}$ [the big house]) but not when they produced bare nouns (e.g., Haus ${ }_{\text {neu }}$ [house]). According to Schriefers et al. (2005), this pattern of results indicates competition between gender-marked lexical items, that is, slower naming latencies for masculine and neuter plural NPs (as compared with the corresponding singular NPs) because of competition between different determiner forms in singular and plural and the reversed pattern for feminine NPs because of lack of determiner form competition. No such effect was found in bare noun naming. However, the authors claimed that the same pattern as in the determiner + adjective NPs was also found in adjective NPs (e.g., großes neu Haus $_{\text {neu }}$ [big house]), thus providing evidence that freestanding morphemes (e.g., determiners) and bound morphemes (e.g., adjective suffixes) are retrieved following the same processing principles.

In contrast to this position but in line with the proposal made by Lapointe and Dell (1989), Costa, Kovacic, Fedorenko, and Caramazza (2003) and Schiller and Caramazza (2003) claimed that the mechanisms by which speakers retrieve freestanding and bound morphemes are different in nature. They argued that gendermarked freestanding morphemes are selected following a selection-by-competition principle. Gender-marked bound morphemes, however, are retrieved as a consequence of a phonological transformation of the base stem form that does not require selection from the lexicon. That is, whereas the selection of determiner forms is subject to competition with other words in the lexicon, the retrieval of inflectional suffixes is not.

The main experimental motivation to postulate different types of processing principles for the retrieval of freestanding and bound morphemes comes-besides from speech errors (see above)from utterance contexts in which the gender congruency effect is observed in the picture-word interference paradigm. The gender congruency effect refers to longer naming latencies when picture names and distractor words have different grammatical genders than when they have the same grammatical gender. The reliable attainment of the gender congruency effect seems to depend on various variables. First, there are some language-specific properties. For example, the gender congruency effect has not been observed in any of the Romance languages tested so far (see overview in Caramazza, Miozzo, Costa, Schiller, \& Alario, 2001). Second, and more important for our purposes here, one property that seems to be crucial is whether the gender of the noun surfaces in the target utterance as a freestanding morpheme or as a bound morpheme. Data from several languages (German, Dutch, and Croatian) consistently showed a gender congruency effect when participants produced utterances in which the gender of the noun was marked by a freestanding morpheme (La Heij, Mak, Sander, \& Willeboordse, 1998; Schiller \& Caramazza, 2003, in press; Schriefers, 1993; Schriefers \& Teruel, 2000; Starreveld \& La Heij, 2004). In contrast, when the gender of the noun was marked by means of an inflectional morpheme attached to another lexical item, the gender congruency effect is rather elusive. Although a gender congruency effect for this latter type of morpheme was first reported in an experiment by Schriefers (1993) in Dutch, both Schiller and Caramazza (2003; in Dutch and German) as well as Costa et al. (2003; in Croatian) were not able to replicate it. In summary, the majority of the experiments so far showed a gender congruency effect when the response included gender-marked free-stranding morphemes-except when the selection of such morphemes does not depend on the gender of the head noun alone (see Caramazza et al., 2001, for an overview).

One possibility is that this contrasting pattern reflects different mechanisms behind the selection of these two different types of morphemes (see for instance the proposal made by Lapointe \& Dell, 1989). Following this idea, we argue that the processes for the selection of freestanding and bound morphemes are different, the first being subject to competition and the second not. Contrary to this line of argumentation, Schriefers et al. (2005) accounted for the instability of the gender congruency effect for bound morphemes by appealing to the position of such morphemes in the utterance. They argued that competition processes might be more difficult to detect by measuring onset naming latencies for elements that occur in noninitial positions of the utterance than for elements that are in initial position. Given that in the studies conducted by Schiller and Caramazza (2003) as well as by Schriefers (1993) bound morphemes tended to appear later in the utterance (second syllable of the first word, e.g., groene vaas [green vase]) than freestanding morphemes (first syllable, e.g., de vaas [the vase]), the lack of an effect for the first type of utterances might be attributed to the location of the gender-marked morpheme in the response. 
However, the issue of whether the location of gender-marked morphemes in the utterance plays a critical role for detecting a reliable gender congruency effect has already been answered experimentally by Costa et al. (2003). In their study, gender-marked bound morphemes appeared in an earlier position (e.g., $m o j_{\text {mas }}$ krevet $_{\text {mas }}$ [my tie] vs. moja $_{\mathrm{fem}}$ kuča $\mathbf{a}_{\mathrm{fem}}$ [my house]; mas $=$ masculine, fem $=$ feminine) than gender-marked freestanding morphemes (vidim $g a_{\text {mas }}$ [I see it] vs. vidim je $e_{\text {fem }}$ [I see it]). Contrary to what Schriefers et al. (2005) would have predicted, a gender congruency effect was present for utterances containing the gender-marked element in final position and was absent for utterances containing the gender-marked element in initial position. However, Schriefers et al. (2005) argued that the possessive pronoun $m y$ (as in $m o j_{\text {mas }}$ krevet $_{\text {mas }}$ [my tie]) is a closed class morpheme and that in all experiments in which closed class morphemes were used, gender congruency effects have been observed so far. Therefore, the absence of a gender congruency effect with closed class morphemes in Costa et al.'s (2003) study should be considered more the exception than the rule.

However, it is unclear why the presence of gender congruency effects should depend on whether the noun's gender surfaces as a closed or open class morpheme in the utterance. According to Schriefers et al. (2005), whenever the gender-marked element corresponds to a closed class morpheme and is located in initial position of the utterance, a gender congruency effect should be present, regardless of whether the gender-marking morpheme is bound or freestanding. If gender congruency effects were present for any gender-marked closed class morpheme regardless of the specific morphological nature (i.e., freestanding vs. bound) in which the gender marking surfaces in the utterance, then Schriefers et al.'s criticism of the Croatian data might be justified. This situation would, in turn, force us to reconsider our conclusion that freestanding and bound morphemes are retrieved following different principles. In the following, we report two experiments that address this issue.

If the hypothesis put forward by Schriefers et al. (2005) was correct, and gender-marked closed class words always lead to a gender congruency effect, then we should observe gender congruency effects for utterances in which the determiner form is gendermarked by means of a bound morpheme. In contrast, if gender congruency effects are restricted only to those utterance formats in which the noun's gender surfaces as a freestanding morpheme (irrespective of its grammatical category), then gender congruency effects should be absent for utterances in which the determiner form is gender marked by means of a bound morpheme. The main goal of the experiments presented below is precisely to test this prediction by asking German native speakers to name pictures by means of NPs that contained either an indefinite or a definite determiner. It is crucial to note that the noun's gender value in German indefinite determiners is marked by a bound morpheme, whereas it surfaces as a freestanding morpheme in definite determiner NPs.

\section{Experiments 1A and 1B: Indefinite and Definite Determiner NP Production}

In Experiment 1A, we tested whether a gender congruency effect is present in German when the noun's gender surfaces as a bound morpheme attached to a closed class word (i.e., ein $[\mathrm{a}(\mathrm{n})]$ vs. eine $[\mathrm{a}(\mathrm{n})])$ in the initial position of utterances. Thus, this experiment is very similar to that conducted in Croatian (i.e., moj

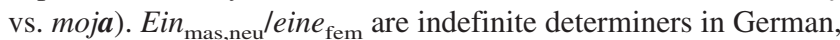
but they behave like adjectives in the sense that their inflectional paradigm is the same as for adjectives, with the $-e$ suffix for the feminine form. German distinguishes three grammatical genders, that is, masculine, feminine, and neuter. Masculine and neuter are marked by the same indefinite determiner ein (e.g., ein ${ }_{\text {mas }}$ Tisch $_{\text {mas }}$ [a table] or ein $_{\text {neu }} B u c h_{\text {neu }}$ [a book]), the feminine form is eine (e.g., eine $_{\text {fem }}$ Tür $_{\text {fem }}$ [a door]). In Experiment 1A, participants were asked to name objects by using indefinite determiner NPs while a gender-congruent or a gender-incongruent distractor word was visually presented. The names of the objects were either masculine or feminine. To assess the sensitivity of our design, we included semantically related and phonologically related distractors.

Experiment 1B tested the complementary situation, that is, when the noun's gender surfaced as a freestanding morpheme such as a definite determiner. Experiment 1B was identical to Experiment 1A except that participants produced definite determiner NPs in Experiment $1 \mathrm{~B}$ instead of indefinite determiner NPs in Experiment $1 \mathrm{~A}$.

\section{Method}

\section{Participants}

All participants were native speakers of German and students at the Radboud Universiteit in Nijmegen, the Netherlands. They were paid a small reward for their participation in the study. None participated in both experiments, and 20 participants took part in each experiment.

\section{Materials}

Fifty-six pictures corresponding to monomorphemic German nouns (28 feminine and 28 masculine; the sets were matched in CELEX frequency and length; Baayen, Piepenbrock, \& Gulikers, 1995) were selected as targets for the experiment. The 28 masculine distractor words selected for the gender-congruent condition for masculine targets were used to create the gender-incongruent condition for the feminine targets and vice versa. These picture-word pairs were not semantically or phonologically related; however, for each target picture name, gender-congruent semantically related and phonologically related distractor words were selected (see Appendix). Pictures were black line drawings presented on a white background that fit a $7 \mathrm{~cm} \times 7 \mathrm{~cm}$ virtual frame. Distractor words were superimposed in black characters across the object (font type and size: Arial, 24 pt).

\section{Procedure}

Participants were tested individually in a dimly-lit sound-attenuated booth. They saw the pictures from a viewing distance of approximately 60 $\mathrm{cm}$. On each trial, a fixation point appeared for $300 \mathrm{~ms}$ followed by the picture and the distractor word, presented for 1,000 ms. In Experiment 1A, participants were instructed to name the pictures as quickly and as accurately as possible with the appropriate indefinite determiner NP in German (e.g., ein $_{\text {mas }}$ Tisch $_{\text {mas }}$ [a table] or eine $_{\text {fem }}$ Tür $_{\text {fem }}$ [a door]). In Experiment 1B, participants were asked to respond with a definite determiner NP (e.g., $d e r_{\text {mas }}$ Tisch $_{\text {mas }}$ [the table] or die $_{\text {fem }}$ Tür $_{\text {fem }}$ [the door]). As soon as a response was given, picture and distractor word disappeared from the screen, and after a short pause of $1,000 \mathrm{~ms}$, the next trial started. If no response was recorded within $2 \mathrm{~s}$, the next trial started automatically. A response was considered invalid when it exceeded the response deadline of 
Table 1

Naming Latencies (in $\mathrm{ms}$ ) and Errors Calculated in Percentages in Experiment $1 \mathrm{~A}$

\begin{tabular}{|c|c|c|c|c|c|c|}
\hline \multirow[b]{3}{*}{ Condition } & \multicolumn{4}{|c|}{ Gender of target } & \multirow[b]{3}{*}{$M$} & \multirow[b]{3}{*}{$S D$} \\
\hline & \multicolumn{2}{|c|}{ Feminine } & \multicolumn{2}{|c|}{ Masculine } & & \\
\hline & Latency $M$ & Error \% & Latency $M$ & Error \% & & \\
\hline Gender congruent & 651 & 4.3 & 665 & 4.3 & 658 & 4.3 \\
\hline Gender incongruent & 659 & 1.6 & 663 & 2.5 & 661 & 2.1 \\
\hline Semantically related & 661 & 4.5 & 679 & 4.5 & 670 & 4.5 \\
\hline Phonologically related & 631 & 3.2 & 643 & 4.1 & 637 & 3.7 \\
\hline
\end{tabular}

$2 \mathrm{~s}$, when it included a speech error, when a wrong determiner or picture name was produced, or when the voice key was triggered incorrectly. Invalid responses were excluded from the reaction time analyses.

\section{Design}

Each experiment consisted of three parts. In a familiarization phase, participants were presented with all the pictures and their corresponding names. Participants were asked to use the designated name for each picture. After this phase, each picture was presented once for $1,000 \mathrm{~ms}$, and participants were asked to name them with the appropriate determiner and picture name, for instance, ein Tisch [a table] in Experiment $1 \mathrm{~A}$ or der Tisch [the table] in Experiment 1B. In the experimental phase, stimuli were presented in four blocks of 56 trials each. Pictures and distractors were presented simultaneously (stimulus onset asynchrony $=0 \mathrm{~ms}$ ). Each block started with an additional warm-up filler trial that was not included in the analysis. Each target appeared once per block but with a different distractor (i.e., gender-congruent, gender-incongruent, semantic, or phonological; 28 [pictures] $\times 2$ [genders] $\times 4$ [conditions] $=224$ [trials + warm-up trials]). Targets also served as gender-congruent and gender-incongruent distractors. ${ }^{1}$ Conditions were equally distributed across blocks. Blocks were randomized individually for each participant with the constraint that targets could have the same gender on no more than 3 consecutive trials. Finally, the order of the blocks was varied across participants. Each experiment lasted approximately $30 \mathrm{~min}$.

\section{Results}

Mean naming latencies and error rates are summarized in Table 1 for Experiment $1 \mathrm{~A}$ and in Table 2 for Experiment 1B. Analyses of variance were run with congruency (gender-congruent vs. gender-incongruent) and gender of target (feminine or masculine) as independent variables. Separate analyses were carried out with participants $\left(F_{1}\right)$ and items $\left(F_{2}\right)$ as random variables.

\section{Experiment $1 A$}

Responses including a speech error, a wrong determiner or picture name, and outliers, that is, naming latencies shorter than $350 \mathrm{~ms}$ and longer than $2,000 \mathrm{~ms}$, were counted as errors. The overall error rate was $3.6 \%$. The main effect of congruency, $F_{1}(1$, $19)=8.28, M S E=1.89, p<.05 ; F_{2}(1,55)=7.15, M S E=0.78$, $p<.05$, was significant, reflecting the fact that more errors were made in the gender-congruent than in the gender-incongruent condition. The main effect of gender of target $\left(F_{1}<1 ; F_{2}<1\right)$ and the interaction between condition and gender of target were not significant $\left(F_{1}<1 ; F_{2}<1\right)$.
In the analyses of naming latencies, the main effect of congruency was not significant $\left(F_{1}<1 ; F_{2}<1\right)$. Feminine targets $(655$ $\mathrm{ms})$ were named slightly faster than masculine targets $(664 \mathrm{~ms})$, but the effect of gender of target was significant only by participants, $F_{1}(1,19)=4.43, M S E=352.49, p<.05 ; F_{2}(1,54)=1.19$, $M S E=2,371.56, n s$. Congruency did not interact with gender of target $\left(F_{1}<1\right), F_{2}(1,54)=1.17, M S E=870.53$, ns. However, semantically related distractors slowed down naming latencies in comparison with gender-congruent distractors, which approached significance by items: $t_{1}(19)=3.17, S D=17.82, p<.01$; $t_{2}(55)=1.87, S D=47.36, p=.67$, and phonologically related distractors sped up naming latencies in comparison with gendercongruent distractors: $t_{1}(19)=3.66, S D=25.49, p<.01$; $t_{2}(55)=3.12, S D=49.16, p<.01$.

There are three main results in Experiment 1A: (a) Gendercongruent and gender-incongruent distractors produce the same amount of interference, (b) semantically related distractors slowed down naming $(12 \mathrm{~ms})$ latencies in comparison with unrelated (gender-congruent) distractors, and (c) phonologically related (21 $\mathrm{ms}$ ) distractors sped up naming latencies in comparison with unrelated (gender-congruent) distractors.

\section{Experiment $1 B$}

The criteria for errors were the same as in Experiment 1A. The overall error rate was $2.4 \%$. The main effects of congruency, $F_{1}(1$, $19)=2.35, M S E=1.29, n s ; F_{2}(1,55)=1.73, M S E=0.63, n s$, and gender of target were not significant $\left(F_{1}<1 ; F_{2}<1\right)$. The interaction between condition and gender of target was not significant, either, $F_{1}(1,19)=1.15$, $n s\left(F_{2}<1\right)$.

In the analyses of naming latencies, the main effect of congruency was significant, $F_{1}(1,19)=11.68, M S E=281.86, p<.01$; $F_{2}(1,55)=4.25, M S E=1,978.39, p<.05$. Feminine targets $(715$ $\mathrm{ms})$ were named more slowly than masculine targets $(693 \mathrm{~ms})$, but the effect of gender of target was not significant, $F_{1}(1,19)=3.32$, $M S E=3,068.04, n s ; F_{2}(1,54)=3.21, M S E=4,552.04, n s$, and, more important, the interaction between congruency and gender of target was not significant, $F_{1}(1,19)=1.51, M S E=1,295.78, n s$;

\footnotetext{
${ }^{1}$ Because of a small error in the design, unfortunately the target Ananas [pineapple] did not appear as a gender-congruent distractor and Bogen [bow] did not appear as a gender-incongruent distractor. Instead, Tasche [bag] and Magnet [magnet] appeared in those conditions, respectively. This error occurred both in Experiment 1A and in Experiment 1B.
} 
Table 2

Mean Naming Latencies (in ms) and Errors Calculated in Percentages in Experiment $1 \mathrm{~B}$

\begin{tabular}{|c|c|c|c|c|c|c|}
\hline \multirow[b]{3}{*}{ Condition } & \multicolumn{4}{|c|}{ Gender of target } & \multirow[b]{3}{*}{$M$} & \multirow[b]{3}{*}{$S D$} \\
\hline & \multicolumn{2}{|c|}{ Feminine } & \multicolumn{2}{|c|}{ Masculine } & & \\
\hline & Latency $M$ & Error \% & Latency $M$ & Error \% & & \\
\hline Gender-congruent & 711 & 2.7 & 679 & 1.8 & 695 & 2.2 \\
\hline Gender-incongruent & 719 & 3.0 & 707 & 3.4 & 713 & 3.2 \\
\hline Semantically related & 722 & 3.9 & 697 & 1.4 & 709 & 2.7 \\
\hline Phonologically related & 674 & 1.4 & 657 & 1.4 & 665 & 1.4 \\
\hline
\end{tabular}

$F_{2}(1,54)=1.45, M S E=2,839.85, n s$. Moreover, semantically related distractors again slowed down naming latencies in comparison with gender-congruent distractors, again approaching significance by items: $t_{1}(19)=3.07, S D=20.64, p<.01 ; t_{2}(55)=$ $1.90, S D=53.52, p=.062$, and phonologically related distractors sped up naming latencies in comparison with gender-congruent distractors: $t_{1}(19)=4.24, S D=31.28, p<.001 ; t_{2}(55)=3.82$, $S D=60.45, p<.001$.

There are three main results in Experiment 1B: (a) Gendercongruent distractors produced less interference $(18 \mathrm{~ms})$ than gender-incongruent distractors, (b) semantically related distractors slowed down naming (14 ms) latencies in comparison with unrelated (gender-congruent) distractors, and (c) phonologically related (30 ms) distractors sped up naming latencies in comparison with unrelated (gender-congruent) distractors.

\section{Combined Analysis of Experiments $1 A$ and $1 B$}

To be able to claim that our results in Experiment $1 \mathrm{~B}$ are statistically different from Experiment 1A, we needed to demonstrate an interaction between congruency and a new factor, experiment, which is a between-subjects factor. Indeed, congruency interacted significantly with experiment, $F_{1}(1,38)=4.18, M S E=$ 206.92, $p<.05 ; F_{2}(1,55)=8.98, M S E=1,128.10, p<.01$. Furthermore, there were some descriptive differences, though not statistically reliable, between the two genders with respect to the magnitude of the congruency effect (i.e., in Experiment 1A, the congruency was $8 \mathrm{~ms}$ for feminine items, whereas it was $2 \mathrm{~ms}$ in the unpredicted direction for masculine items; in Experiment 1B, it was $8 \mathrm{~ms}$ for feminine items, whereas it was $28 \mathrm{~ms}$ for masculine items). However, as mentioned above, congruency did not interact with gender of target in either experiment, and the three-way interaction between congruency, gender of target, and experiment was not significant either, $F_{1}(1,38)=1.29, M S E=617.09$, $n s$; $F_{2}(1,54)=1.50, M S E=1,118.02$, ns.

\section{Discussion}

Gender-congruent and gender-incongruent distractors affected the production of utterances containing gender-marked bound morphemes to the same extent (Experiment 1A). However, when the utterances contained gender-marked freestanding determiners, gender-congruent distractors led to faster naming latencies than gender-incongruent distractors (Experiment 1B). ${ }^{2}$ Furthermore, given that in Experiment $1 \mathrm{~A}$ the gender-marked element was an indefinite determiner, this result corroborates the empirical gener- alization put forward by Costa et al. (2003), that is, the presence of a gender congruency effect is independent of whether the noun's gender surfaces in the context of closed class or open class words. That is, gender congruency effects are sometimes present and sometimes absent when the utterance contains closed class words (such as determiners). This observation contrasts with the empirical generalization proposed by Schriefers et al. (2005) when stating that in all experiments in which closed class words have been used, the gender congruency effect has been observed. The results of German (this study) and Croatian (Costa et al., 2003) demonstrated that such a generalization does not hold.

The results of Experiment 1A also help us to better characterize the conditions under which gender congruency effects can be observed. They show that such an effect does not depend on the specific grammatical class of the gender-marked element. In fact, a gender congruency effect has been obtained with the exact same materials in Experiment 1B, when participants produced utterances in which the gender-marking of the determiner form was carried by a freestanding morpheme (determiner NPs of the type der Tisch [the table] or die Tür [the door]; see also Schiller \& Caramazza, 2003). That is, utterances containing determiner forms sometimes lead to gender congruency effect and sometimes do not.

What seems to be critical is whether the noun's gender surfaces as a freestanding or bound morpheme. When the gender-marking surfaces as a freestanding morpheme that corresponds to a closed class word, gender congruency effects are observed; however, when it surfaces as a bound morpheme attached to a closed class word, gender congruency effects are absent. Similarly, when the gender-marking surfaces as a bound morpheme attached to an open class word, gender congruency effects are not present either

\footnotetext{
${ }^{2}$ One may argue, however, that participants were able to prepare a larger amount of the response in Experiment 1A than in Experiment 1B so that the gender-congruency effect may have been practically invisible in Experiment 1A. More specifically, in Experiment 1A, responses started with the indefinite determiners ein $_{\text {mas }}$ or eine $_{\text {fem }}$, whereas in Experiment 1B, responses started with the definite determiners $d e r_{\text {mas }}$ or $d i e_{\text {fem }}$. Thus, masculine and feminine responses have two segments (i.e., a diphthong and a consonant: ein /ain/) overlap in Experiment 1A, whereas they have only one segment (i.e., a consonant: $d / \mathrm{d} /$ ) overlap in Experiment 1B. Moreover, the indefinite determiners ein and eine have different syllable structures, that is, ein and ei-ne. However, Cholin, Schiller, and Levelt (2004) recently demonstrated in two experiments that differences in syllable structure spoil preparation effects. Therefore, the amount of response preparation was presumably very similar in Experiments $1 \mathrm{~A}$ and $1 \mathrm{~B}$, that is, a diphthong and a consonant, respectively.
} 
(with the unique exception of Schriefers, 1993; Experiment 2). In this context, the results from Costa et al. (2003) prove to be relevant as they demonstrate that the position of the gendermarked morpheme in the utterance is irrelevant for the attainment of gender congruency effects. Consistent with the suggestion made by Lapointe and Dell (1989), it appears that the retrieval of freestanding gender-marked morphemes is subject to competitive processes, as the retrieval of any other freestanding lexical item, presumably because they have to be actively inserted, whereas the retrieval of bound morphemes is not competitive, presumably because they form part of syntactic frames and therefore do not have to be inserted.

\section{Conclusion}

In this observation, we investigated the question of whether freestanding and bound morphemes are retrieved following the same processing principles. Experimental studies generally demonstrated gender congruency effects that were reliably observed when the utterance format contained a gender-marked freestanding morpheme. This phenomenon has been shown to be present in a variety of languages (Dutch, German, and Croatian), in different utterance formats (NPs and sentences), with several different types of morphemes (pronouns, determiners), and irrespective of the position of the freestanding morpheme (phrase-initial or final). The situation is different for utterances containing gender-marked bound morphemes. In this case, the gender congruency effect has not been observed in German (with color adjectives or indefinite determiners), or in Croatian (with possessive pronouns), and the results from Dutch are mixed. Thus, at present the experimental evidence seems to be in agreement with Lapointe and Dell's (1989) proposal that the freestanding and bound morphemes are retrieved following distinct processing principles, the first type being subject to competition and the second not.

\section{References}

Baayen, R. H., Piepenbrock, R., \& Gulikers, L. (1995). The CELEX lexical database [CD-ROM]. Philadelphia: Linguistic Data Consortium, University of Pennsylvania.

Bock, K., \& Levelt, W. J. M. (1994). Language production: Grammatical encoding. In M. A. Gernsbacher (Ed.), Handbook of psycholinguistics (pp. 945-984). San Diego, CA: Academic Press.

Caramazza, A., Miozzo, M., Costa, A., Schiller, N. O., \& Alario, F.-X.
(2001). A cross-linguistic investigation of determiner production. In E. Dupoux (Ed.), Language, brain and cognitive development: Essays in honor of Jacques Mehler (pp. 209-226). Cambridge, MA: MIT Press.

Cholin, J., Schiller, N. O., \& Levelt, W. J. M. (2004). The preparation of syllables in speech production. Journal of Memory and Language, 50, 47-61.

Costa, A., Kovacic, D., Fedorenko, E., \& Caramazza, A. (2003). The gender-congruency effect and the selection of freestanding and bound morphemes: Evidence from Croatian. Journal of Experimental Psychology: Learning, Memory, and Cognition, 29, 1270-1282.

Dell, G. S. (1990). Effects of frequency and vocabulary type on phonological speech errors. Language and Cognitive Processes, 5, 313-349.

Garrett, M. F. (1982). Production of speech: Observations from normal and pathological language use. In A. W. Ellis (Ed.), Normality and pathology in cognitive functions (pp. 19-76). London: Academic Press.

Garrett, M. F. (1993). Errors and their relevance for models of language production. In G. Blanken, J. Dittman, H. Grimm, J. C. Marshall, \& C.-W. Wallesch (Eds.), Linguistic disorders and pathologies: An international handbook (pp. 72-92). Berlin, Germany: De Gruyter.

La Heij, W., Mak, P., Sander, J., \& Willeboordse, E. (1998). The gender congruency effect in picture-word tasks. Psychological Research, 61, 209-219.

Lapointe, S. G. (1985). A theory of verb form use in the speech of agrammatic aphasics. Brain and Language, 24, 100-155.

Lapointe, S. G., \& Dell, G. S. (1989). A synthesis of some recent work in sentence production. In G. N. Carlson \& M. K. Tanenhaus (Eds.), Linguistic structure in language processing (pp. 107-156). Dordrecht, the Netherlands: Kluwer Academic Publishers.

Schiller, N. O., \& Caramazza, A. (2003). Grammatical feature selection in noun phrase production: Evidence from German and Dutch. Journal of Memory and Language, 48, 169-194.

Schiller, N. O., \& Caramazza, A. (in press). Grammatical gender selection and the representation of morphemes: The production of Dutch diminutives. Language and Cognitive Processes.

Schriefers, H. (1993). Syntactic processes in the production of noun phrases. Journal of Experimental Psychology: Learning, Memory, and Cognition, 19, 841-850.

Schriefers, H., Jescheniak, J. D., \& Hantsch, A. (2005). Selection of gender-marked morphemes in speech production. Journal of Experimental Psychology: Learning, Memory, and Cognition, 31, 159-168.

Schriefers, H., \& Teruel, E. (2000). Grammatical gender in noun phrase production: The gender interference effect in German. Journal of Experimental Psychology: Learning, Memory, and Cognition, 26, 1368 1377.

Starreveld, P. A., \& La Heij, W. (2004). Phonological facilitation of grammatical gender retrieval. Language and Cognitive Processes, 19, $677-711$. 


\section{Appendix}

Stimulus Materials in Experiments 1A and 1B

\begin{tabular}{|c|c|c|c|c|}
\hline \multirow[b]{2}{*}{$\begin{array}{c}\text { Target picture } \\
\text { names }\end{array}$} & \multicolumn{4}{|c|}{ Distractor word condition } \\
\hline & Gender-congruent & Gender-incongruent & $\begin{array}{l}\text { Semantically } \\
\text { related }\end{array}$ & $\begin{array}{l}\text { Phonologically } \\
\text { related }\end{array}$ \\
\hline \multicolumn{5}{|c|}{ Masculine } \\
\hline Schlitten [sled] & Zahn [tooth] & Gabel [fork] & Bob $[\mathrm{bob}]$ & Schlips[tie] \\
\hline Knopf [button] & Vogel [bird] & Lupe [magnifying glasses] & Verschluß [zipper] & Knochen [bone] \\
\hline Teller [plate] & Affe [monkey] & Leiter [ladder] & Deckel [lid] & Test [test] \\
\hline Fuß $[$ foot $]$ & Hammer [hammer] & Sonne $[$ sun] & Arm [arm] & Fuchs [fox] \\
\hline Tisch [table] & Fuß [foot] & Rose [rose] & Sessel [arm chair] & Titel [title] \\
\hline Affe [monkey] & Kamm $[\mathrm{comb}]$ & Tasse [cup] & Bär [bear] & Affront [insult] \\
\hline Frosch [frog] & Baum [tree] & Kasse [cash register] & Salamander [salamander] & Frost [frost] \\
\hline Hund $[\mathrm{dog}]$ & Teller [plate] & Birne [pear] & Wolf [wolf] & Husten $[$ cough] \\
\hline Ärmel [sleeve] & Mund [mouth] & Ananas [pineapple] & Kragen [collar] & Ärger [annoyance] \\
\hline Hammer [hammer] & Rock [skirt] & Tür [door] & Bohrer [drill] & Handel [trade] \\
\hline Bogen [bow] & Knopf [button] & Ziege [goat] & Speer [spear] & Boden [ground] \\
\hline Koffer [suitcase] & Zweig [branch] & Ente [duck] & Beutel [bag] & Kopf [head] \\
\hline Zweig [branch] & Korb [sled $]$ & Gans [goose] & Stamm [trunk $]$ & Zweifel [doubt] \\
\hline $\mathrm{Kamm}[\mathrm{comb}]$ & Schlitten [sled] & Flasche [bottle] & Föhn [hair-dryer] & Kamin [hearth] \\
\hline Korb [basket] & Hund $[\operatorname{dog}]$ & Blume [flower] & Eimer [bucket] & Kolben [piston] \\
\hline Ofen [stove] & Ärmel [sleeve] & Trommel [drum] & Herd [stove] & Offizier [officer] \\
\hline Stuhl [chair] & Tiger [tiger] & Vase [vase] & Hocker [stool] & Sturz [fall] \\
\hline Rock [skirt] & Stern [star] & Palme [palm tree] & Anzug [suit] & Rost [rust] \\
\hline Baum [tree] & Finger [finger] & Hose [pants] & Strauch [bush] & Bau [construction] \\
\hline Besen [broom] & Frosch $[$ frog] & Ratte [rat] & Rechen [rake] & Becher [cup] \\
\hline Finger [finger] & Tisch [table] & Banane [banana] & Zeh [toe] & Filter [filter] \\
\hline Kreis [circle] & Besen [groom] & Mauer [wall] & Würfel [dice] & Kreisel [spinning top] \\
\hline Mund [mouth] & Stuhl [chair] & Kette [chain] & Rachen [throat] & Mut [courage] \\
\hline Sattel [saddle] & Bogen [bow] & Glocke [bell] & Zaum [leash] & Sand [sand] \\
\hline Stern [star] & Koffer [suitcase] & Feder [feather] & Planet [planet] & Steg [pier] \\
\hline Tiger [tiger] & Sattel [saddle] & Bombe [bomb] & Löwe [lion] & Tip [hint] \\
\hline Vogel [bird] & Kreis [circle] & Nase [nose] & Fisch [fish] & Vogt [protector] \\
\hline Zahn [tooth] & Ofen [stove] & Kerze [candle] & Gaumen [palate] & Zapfen [cone] \\
\hline \multicolumn{5}{|c|}{ Feminine } \\
\hline Tür [door] & Rose [rose] & Fuß [foot] & Luke [shutter] & Türkei [Turkey] \\
\hline Sonne [sun] & Feder [feather] & Koffer [suitcase] & Erde [earth] & Sonde [explorer] \\
\hline Ratte [rat] & Banane [banana] & Mund [mouth] & Maus [mouse] & Rasse [race] \\
\hline Gans [goose] & Palme [palm tree] & Ärmel [sleeve] & Pute [turkey] & Gabe [donation] \\
\hline Kerze [candle] & Sonne [sun] & Besen [groom] & Fackel [torch] & Kerbe [incision] \\
\hline Leiter [ladder] & Kasse [cash register] & Knopf [button] & Treppe [stairs] & Leitung [direction] \\
\hline Bombe $[$ bomb] & Ente [duck] & Tisch [table] & Granate [grenade] & Bohne [bean] \\
\hline Hose [pants] & Tür [door] & Teller [plate] & Jacke [jacket] & Hocke [squat] \\
\hline Birne [pear] & Gabel [fork] & Frosch [frog] & Melone [melon] & Bilanz [balance] \\
\hline Palme [palm tree] & Tasse [cup] & Magnet [magnet] & Eiche [oak tree] & Panne [breakdown] \\
\hline Nase $[$ nose $]$ & Lupe [magnifying glass] & Stern $[\mathrm{star}]$ & Wange [cheek] & Natur [nature] \\
\hline Gabel [fork] & Hose [pants] & Baum [tree] & Kelle [tablespoon] & Galle [gall] \\
\hline Rose [rose] & Leiter [ladder] & Finger [finger] & Tulpe [tulip] & Rosine [raisin] \\
\hline Flasche [bottle] & Birne [pear] & Affe [monkey] & Dose [box] & Flamme [flame] \\
\hline Vase [vase] & Glocke [bell] & Hund $[\operatorname{dog}]$ & Karaffe [carafe] & Variante [variant] \\
\hline Banane [banana] & Tasche [bag] & Stuhl [chair] & Orange [orange] & Bande [gang] \\
\hline Blume [flower] & Ratte [rat] & Sattel [saddle] & Staude [bushes] & Bluse [blouse] \\
\hline Ente $[$ duck $]$ & Kette [chain] & Zweig [branch] & Möwe [gull] & Energie [energy] \\
\hline Feder [feather] & Ziege [goat] & Kreis [circle] & Daune [down feather] & Festung [bastion] \\
\hline Glocke [bell] & Blume [flower] & Tiger [tiger] & Klingel [bell] & Glosse [gloss] \\
\hline Kasse [cash register] & Flasche [bottle] & Ofen [stove] & Theke [bar] & Katze [cat] \\
\hline Kette [chain] & Gans [goose] & Hammer [hammer] & Fessel [handcuffs] & Kehle [throat] \\
\hline Lupe [magnifying glass] & Mauer [wall] & Schlitten [sled] & Brille [pair of glasses] & Luft [air] \\
\hline Mauer [wall] & Trommel [drum] & Vogel [bird] & Wand [wall] & Maut [toll] \\
\hline Ananas [pineapple] & Vase [vase] & Kamm [comb] & Zitrone [lemon] & Analyse [analysis] \\
\hline Tasse [cup] & Nase [nose] & Zahn [tooth] & Schale [food bowl] & Tafel [tablet] \\
\hline Trommel [drum] & Bombe [bomb] & Korb [basket] & Gitarre [guitar] & Trophäe [trophy] \\
\hline Ziege [goat] & Kerze [candle] & Rock [skirt] & Kuh $[$ cow $]$ & Zierde [outfit] \\
\hline
\end{tabular}

